\title{
EL DEBER DE BUENA FE EN LOS PROCEDIMIENTOS LABORALES: NOCIÓN, MANIFESTACIÓN Y PROBLEMÁTICA
}

\author{
PABLO CifuENTES \\ Abogado
}

\begin{abstract}
RESUMEN: Siguiendo los pasos de reformas efectuadas en el derecho comparado, el nuevo procedimiento laboral ha incorporado expresamente a la buena fe como uno de sus principios informantes. El presente trabajo pretende demostrar que dicha inclusión implica la vulneración de distintos derechos fundamentales de las partes, fin para el cual se efectúa una aproximación a la noción doctrinaria de buena fe procesal, se exponen algunas de sus manifestaciones en el nuevo procedimiento laboral, y finalmente se concluye en base a las problemáticas que resultan de su aplicación.
\end{abstract}

Palabras clave: Buena fe, principios, procedimiento, procedimientos laborales; Código del Trabajo.

ABSTRACT: Following in the footsteps of reforms in comparative law, the new labor procedure expressly incorporated the good faith as one of its key principles. This paper aims to demonstrate that such inclusion implies the infringement of various fundamental rights of the parties, purpose for which it makes a approach to the doctrinaire notion of procedural good faith, presents some of its manifestations in the new labor procedures, and finally concludes on the basis of the problems resulting from their application.

Key words: Good faith, principles, procedure, labor procedures, Labor Code.

\section{INTRODUCCIÓN}

Acorde con las transformaciones que han operado en el derecho comparado europeo ${ }^{1}$ desde finales del siglo XIX, el legislador estimó necesario dotar al procedimiento laboral de un influjo moralizante ${ }^{2}$, inédito en nuestro ordenamiento procesal, y así, dentro de todos

\footnotetext{
1 Siendo uno de los ejemplos más notables el Codice di procedura civile italiano de 1940, dada su fuerte influencia en Europa y América Latina, el cual prescribe a este respecto: "Deber de lealtad y de probidad. Las partes y sus defensores tienen el deber de comportarse en juicio con lealtad y probidad. En caso de incumplimiento por los defensores de este deber, el juez deberá dar cuenta a las autoridades que ejercitan sobre ellos la potestad disciplinaria". Puede leerse más en MONTERO, J. Los Principios Politicos de la nueva Ley de Enjuiciamiento Civil. Los poderes del juez y la oralidad. Valencia: Tirant lo Blanch, 2001, pp. 106 y ss. De manera más reciente, en España, la Ley Orgánica 6/1985, de 1 de julio, del Poder Judicial, dispone de manera general, en su artículo 11.1 que "en todo tipo de procedimiento se respetarán las reglas de la buena fe", y en su artículo 546.2, específicamente respecto de los abogados, que "en su actuación ante los Juzgados y Tribunales (...) se sujetarán al principio de buena fe". De igual modo la Ley de Enjuiciamiento Civil del año 2000, regula en su artículo 247 el "respeto a las reglas de la buena fe procesal", disponiendo en su $N^{\circ} 1$ que "los intervinientes en todo tipo de procesos deberán ajustarse en sus actuaciones a las reglas de la buena fe". Lo expuesto, es tratado con detención por el mismo Montero en: MONTERO. J. "Sobre el mito autoritario de la buena fe procesal", en: Montero, J. (coord.). Proceso Civil e Ideología. Valencia: Tirant lo Blanch, 2006.

${ }^{2}$ LARroucau, M.M. "La buena fe procesal y el deber de colaboración de las partes en los procedimientos laborales", en: Revista. Chilena de Derecho del Trabajo y de la Seguridad Social, vol. 1, $\mathrm{N}^{\circ}$ 1, p. 68. Santiago: Universidad de Chile, 2010. Y es que "la función o papel que se ha atribuido a la buena fe es la de corregir el derecho estricto, haciendo penetrar la regla moral en el Derecho positivo". AGUAD, A. y PIZARRO, C. "Obligaciones y Responsabilidad Civil", en Revista Chilena de Derecho Privado No 14, p. 169, 2006. Reafirma lo expuesto Picó i Junoy, para quien la consagración expresa de la buena fe como principio procesal "es una de las vías más eficaces para introducir un con-
} 
los cambios negativos que ha traído consigo la reforma procesal laboral, impulsada por la ley $\mathrm{N}^{\circ} 20.087$, uno de los tantos que merece especial atención es el de la consagración expresa de la buena fe como principio informante de este nuevo procedimiento.

En Chile, la buena fe ha sido tratada principalmente dentro del Derecho Civil, encontrándose consagrada en los artículos $1546^{3}$ y $706^{4}$ del Código Civil en lo que se ha llamado su faz objetiva y subjetiva, respectivamente. Mas su consagración y aplicación en materia procesal, en cambio, y pese a que una tendencia procesal ha tendido a encontrar puntos de encuentro entre los derechos materiales -subjetivos y fundamentales- y el proceso $^{5}$, es algo nuevo en nuestra legislación.

Si bien el Código de Procedimiento Civil -en adelante CPC- contempla algunas normas de cuyo contenido puede colegirse que al legislador no le era del todo indiferente la disposición subjetiva de las partes al momento de efectuar actuaciones dentro del proceso ${ }^{6}$, estas versan sobre conductas específicas y acotadas que se refieren a hechos positivos de una de las partes que pudieran significar un entorpecimiento de este, sin que se consagrase un principio o deber general de buena fe. Es decir, se incentivarían ciertas abstenciones respecto de conductas maliciosas, mas no se impulsarían patrones conductuales que se tradujeran en deberes positivos para los litigantes. Lo dicho, es del todo explicable no solo por la marcada raigambre decimonónica de nuestro $\mathrm{CPC}^{7}$, en el que las partes son dueñas del proce-

tenido ético-moral en el ordenamiento jurídico". PICO I JUNOY, J. El principio de la buena fe procesal. p. 18. Disponible en: http://www.justiciayderecho.org/revista4/articulos/EL\%20PRINCIPIO\%20DE\%20\%LA\%20BUENA\%20FE\%20 PROCESAL\%20Joan\%20Pico\%20i\%20Jonoi.pdf

${ }^{3}$ Artículo 1546. "Los contratos deben ejecutarse de buena fe, y por consiguiente obligan no solo a lo que en ellos se expresa, sino a todas las cosas que emanan precisamente de la naturaleza de la obligación, o que por la ley o la costumbre pertenecen a ella".

4 Artículo 706. "La buena fe es la conciencia de haberse adquirido el dominio de la cosa por medios legítimos, exentos de fraude y de todo otro vicio. Así en los tírulos translaticios de dominio la buena fe supone la persuasión de haberse recibido la cosa de quien tenía la facultad de enajenarla, y de no haber habido fraude ni otro vicio en el acto o contrato. Un justo error en materia de hecho no se opone a la buena fe. Pero el error en materia de derecho constituye una presunción de mala fe, que no admite prueba en contrario."

5 Carreta, F. "Deberes Procesales de las partes en el Derecho Procesal Civil chileno: Referencia a la buena fe procesal y al deber de coherencia", en: Revista Chilena de Derecho vol. 21, No 1, p. 117. Santiago: Pontificia Universidad Católica, 2008. Disponible en: http://www.scielo.cl/pdf/revider/v2 1 n1/art0.5.pdf [consultado el 30 de diciembre de 2010]

${ }^{6}$ Así, por ejemplo, el artículo 88 del CPC, que en sus incisos 1 y 2 prescribe que, "La parte que haya promovido y perdido dos o más incidentes en un mismo juicio, no podrá promover ningún otro sin que previamente deposite en la cuenta corriente del tribunal la cantidad que este fije. El tribunal de oficio y en la resolución que deseche el segundo incidente determinará el monto del depósito. Este depósito fluctuará entre una y diez unidades tributarias mensuales y se aplicará como multa a beneficio fiscal, si fuere rechazado el respectivo incidente. El tribunal determinará el monto del depósito considerando la actuación procesal de la parte y si observare mala fe en la interposición de los nuevos incidentes podrá aumentar su cuantía hasta por el duplo. La parte que goce de privilegio de pobreza en el juicio, no estará obligada a efectuar depósito previo alguno."

7 Que plasmaría una concepción del proceso propia de los ideales liberales de la época, según la cual, acorde a Calamandrei, "la función del derecho mira, en primer término, al mantenimiento del orden entre los coasociados y a la conciliación de los contrapuestos intereses individuales, y la justicia aparece así como servicio público puesto a disposición de los mismos", razón por la cual la jurisdicción se abocaría, principalmente, a la defensa de los derechos subjetivos, excluyendo la posibilidad de injerencias estatales que condicionaran la conducta de los particulares. Calamandrei citado en: MONTERO, J., "Sobre el mito,. . (n. 1), p. 302. 
so ${ }^{8}$-excluyéndose, bajo esta visión, la posibilidad de un dirigismo conductual por parte del Estado-, sino también por la mera constatación de que la consagración de la buena fe como principio aplicable dentro del proceso, en general, es algo relativamente reciente, ligado a la aparición y expansión de ciertas ideologías totalitarias a principios del siglo XX -el comunismo y socialismo, como se verá-.

De todos modos, con independencia de que se estimase que la buena fe era un principio general que irradiaba todas la áreas del Derecho, la situación actual tiene un impacto y repercusiones diversas a que si se tratara de la aplicación extensiva de un mero principio general del Derecho, por haberse transformado en una norma de aplicación directa $^{9}$ a la cual se deben someter las partes.

Desde ya vale advertir que no es lo mismo sancionar y proscribir actuaciones específicas que puedan considerarse efectuadas de mala fe -por entrampar innecesariamente el curso progresivo del proceso, etc.- a establecer un principio de buena fe cuya efectividad obligue a las partes a ajustar su conducta procesal por medio de actos positivos, lo que en sí resulta bastante problemático. $Y$ es que la exigencia legal de observar un determinado comportamiento o conducta será siempre a costa de la autonomía y libertad de los particulares, lo que dentro del proceso, inevitablemente limitará las posibilidades de defensa de sus intereses, poniendo en cuestión la real existencia de un debido proceso.

Pero, ¿qué es la buena fe procesal y cuál es la motivación tras su inclusión como principio informante del proceso? Antes de referirnos a la forma en que esta ha sido consagrada dentro del nuevo procedimiento laboral'y a sus manifestaciones e implicancias, parece prudente sugerir una respuesta a estas interrogantes, que el legislador, al no definir qué es la buena fe en el proceso, ha dejado abiertas.

\section{CONCEPTO Y FINES MORALIZANTES DE LA BUENA FE PROCESAL}

\subsection{APROXIMACIÓN A UN CONCEPTO Y DIFICULTADES PARA SU DETERMINACIÓN}

La buena fe, acorde al diccionario de la RAE, corresponde a las cualidades de rectitud y honradez, y, circunscrita al contexto del Derecho, al criterio de conducta al que ha de adaptarse el comportamiento honesto de los sujetos de derecho. Estas nociones, adaptadas al ámbito del proceso, son las que han servido de base a las diversas definiciones doctrinales y jurisprudenciales que, a falta de una definición legal, han tomado a su cargo establecer la significación del concepto de buena fe procesal.

Doctrinariamente, esta ha sido definida por diversos autores, sin que exista un concepto único y conteste que permita delimitar su sentido y alcance con precisión. Así se ha dicho - por nombrar algunas opiniones- que la buena fe procesal es aquella que "impone a

\footnotetext{
${ }^{8}$ Lo que en sí guarda mucha relevancia respecto de la forma en que se desenvolvía el proceso, pues como explica Montero Aroca, "para la concepción liberal la titularidad de verdaderos derechos subjetivos privados, es decir, la existencia de un amplio ámbito de autonomía de voluntad en las relaciones jurídicas materiales de derecho privado, extendía su virtualidad hasta comprender la titularidad de verdaderos derechos subjetivos procesales, consistentes, no ya en poder acudir al proceso, esto es, a pedir la tutela de aquellos derechos materiales, sino en poder determinar la manera de hacer ese proceso". Y así, "cuando se decía que las partes eran las dueñas del proceso se estaba diciendo algo que debía entenderse de modo prácticamente literal". MONTERO, J., "Sobre el mito... (n. 1), p. 306.

9 PICO I JUNOY, J., op. cit. (n. 2), p. 13.
} 
Pablo Cifuentes / El deber de buena fe en los procedimientos laborales: noción, manifestación y problemática

las partes litigantes el deber -de- rectitud, honradez y buen proceder en la defensa de sus intereses jurídicos en el marco de un proceso judicial", que "exige a los contendientes una actuación leal en el uso de pretensiones, defensas o recursos", y que por tanto, implica una sanción "a cualquier exceso en el caso de expedientes dilatorios o pretensiones infundadas"10; un principio concebido bajo una visión utópica del proceso "conforme al cual las partes tendrían un deber de probidad, lealtad, colaboración con la justicia y veracidad de los actos procesales" 11 y, la manifestación en el ámbito jurisdiccional del principio general de la buena fe, el cual no solo desplegaría su eficacia en el campo del derecho privado sino también en el público, en orden a preservar un mínimo de conducta ética en todas las relaciones jurídicas ${ }^{12}$.

Mas los inconvenientes al momento de definir la buena fe procesal, van más allá de lo que puede estimarse como una diversa comprensión de los autores respecto de esta, y es que la noción misma de buena fe es una inherentemente imprecisa, de carácter cambiante y contornos difusos. Como observa Picó i Junoy, se trata de un concepto juridico indeterminado, por lo que a su respecto solo pueden efectuarse meras aproximaciones conceptuales ${ }^{13}$, y es que como tal, su contenido podrá vạriar dependiendo del período histórico de que se trate, de la cultura y de los valores que se estimen primordiales dentro de una comunidad determinada, no pudiendo, por tanto, ser plasmada con un sentido universal e inmutable.

Por lo expuesto, una de las dificultades que -de comienzo- puede aparejar la inclusión de la buena fe como principio informante del procedimiento laboral, es una común a los conceptos jurídicos indeterminados, la cual es la discrecionalidad que estos arriesgan y la correlativa incertidumbre que conllevan. Ello, pues queda entregada a los jueces la misión de determinar su contenido acorde a cada caso concreto, provocando una constante tensión con la seguridad jurídica ${ }^{14}$; cuestión patente al tratarse de un concepto de claro contenido ético, moral y axiológico, que difícilmente podrá definirse de manera conteste en el contexto de una sociedad pluralista y democrática, en la que coexisten diversos valores y códigos éticos ${ }^{15}$.

\subsection{LOS FINES MORALIZANTES DE LA BUENA FE PROCESAL}

Se ha visto que pese a la falta de una concepción única respecto de qué se debiera entender como buena fe dentro del proceso, existe una cierta unanimidad en la doctrina -sea que se esté a favor o en contra de su inclusión- en cuanto a señalar que esta implica el aca-

\footnotetext{
10 BENITEZ, E. "Reflexiones en torno a la propuesta de reforma al procedimiento civil chileno: Il Principios procesales relativos a las partes", en: Revista Chilena de Derecho vol. 34, N³, p. 592. Santiago: Pontificia Universidad Católica de Chile, 2007. Disponible en: http:/www.scielo.cl/sielo.php?pid=s0718-34372007000300014\&sript=si_arttext [consultado el 30 de diciembre de 2010]

11 PALAVECINO, C. "El retorno del inquisidor. Las potestades judiciales en materia probatoria en el Procedimiento Laboral chileno", en: Revista Laboral Chilena, $\mathrm{N}^{\circ} 173,2009$, p. 74.

12 PICO I JUNOY, J., op. cit. (n. 2), p. 3

13 Pico I JunoY, J., op. cit. (n. 2), p. 19

14 HUNTER, I. "No hay buena fe sin interés: La buena fe procesal y los deberes de veracidad, completitud y colaboración", en: Revista de Derecho vol. XXI, N $2 ; 2008$, p. 152. Disponible en: http://www.scielo.cl/pdf/revider/v21n2/art07.pdf [consultada 30 de diciembre de 2010].

15 Ibid.
} 
tamiento de las partes a ciertas conductas positivas y abstenciones, que se encuentren contestes con nociones tan vagas como lo son la moral y lo correcto. Lo expuesto ha permitido concluir respecto de los fines moralizantes tras la inclusión de este principio -que no por nada también es denominado "principio de moralidad", de la "lealtad procesal" o de "probidad procesal"16_. Fines que se condicen con ideales de justicia social, buisqueda de la verdad material y realización del Derecho objetivo.

De este modo, se ha sostenido que con el principio de buena fe:

\begin{abstract}
"se busca que el proceso sea efectivamente un mecanismo para conseguir la justicia, evitando las posibles inmoralidades de que puedan servirse las partes en el ámbito procesal, para obtener una victoria a toda costa (...); conseguir que triunfe siempre la verdad y que todos los que participan en una relación procesal ajusten sus actuaciones a las pautas éticas más elementales, reprobando la práctica de cualquier actuación que configure una utilización dolosa o fraudulenta del proceso"17; que la buena fe procesal "constituye una excelente atalaya desde la cual es posible observar el nivel ético de una ley de enjuiciamiento", de momento que esta, "no puede alentar la conducta maliciosa o fraudulenta de las partes, ni permitir que venza el más diestro en el uso de las normas procesales, sino el que tenga razón" 18 .
\end{abstract}

Lo dicho, en estricta relación con la concepción del proceso que dio origen a este principio, que como explica Montero Aroca, consistió en 'la idea política de que el proceso civil no es una contienda o lucha entre partes parciales, que 'pelean' por lo que creen que les corresponde, y ante un tercero imparcial", sino que "un medio para la búsqueda de la única solución legal, la basada en la verdad objetiva, medio en el que colaboran las partes -especialmente sus abogados-y el juez"; colaboración en la que el juez, "asume deberes, no frente a las partes, sino para con la sociedad" 19 .

Así, el comunismo y el socialismo, que concibieron al proceso como una herramienta para satisfacer intereses públicos por sobre la visión de este como un medio para resolver conflictos entre particulares -comprensible en un contexto de rechazo a los derechos individuales y a la propiedad privada- impusieron a las partes deberes de colaboración y participación con el juez para lograr el esclarecimiento de lo que se llamó la verdad objetiva o material, que correspondería a la verdad verdadera -para diferenciarla de la verdad formal de los sistemas procesales burgueses- que se traducían en deberes, "ya no de aportar los hechos al proceso informando al juez, sino de hacerlo sin esconder hecho alguno y haciéndolo siempre de manera veraz, de modo que -las partes- han de llevar al proceso todo aquello de lo que tienen conocimiento". Se entendía ya en ese entonces, como "un deber de veracidad e integridad o, de otra manera, de lealtad y probidad" para lograr el preciado fin de la realización del Derecho objetivo - manifestación misma de la voluntad del Estado-, en cuya obser-

\footnotetext{
16 ROMERo, A. "El principio de la buena fe procesal y su desarrollo en la jurisprudencia, a la luz de la doctrina de los actos propios", en: Revista Chilena de Derecho vol. 30, N 1, p. 169. Santiago: Pontificia Universidad Católica de Chile, 2003.

${ }^{17}$ Ibid.

${ }^{18}$ PICO I JUNOY, J., op. cit. (n. 2), p. 2

${ }^{19}$ Montero, J., "Sobre el mito... (n. 1), p. 337.
} 
vancia residía el respeto a la autoridad; cuestión que no podía confiarse a la discreción de las partes y sus egoístas intereses ${ }^{20}$.

Más tranquilo con el hecho de que el proceso transite de ser un medio para la resolución de conflictos entre particulares, a ser una herramienta de justicia social, Picó i Junoy afirma que "la nueva recepción normativa de la buena fe procesal se debe al hecho histórico del cambio de percepción de la naturaleza jurídica del proceso, en la que se asume su naturaleza pública", rechazando este autor que dicha evolución pueda deberse a razones ideológicas, ligadas a visiones fascistas o autoritarias del proceso, estimándolo "una cuestión predominantemente técnica más que política" ${ }^{21}$. Esta misma visión, mas sin referirse a una decisión de fondo de tipo técnica o político-ideológica -qủe de todos modos subyace-, es la que sostiene Carretta, al señalar que el objetivo del proceso, "es la decisión del conflicto, que interesa al Estado como receptor de una conciencia colectiva de justicia social"22.

\section{LA BUENA FE COMO PRINCIPIO INFORMANTE DEL PROCEDIMIENTO LABORAL}

\subsection{CONSAgRación de la BUENA FE}

Dispone el artículo 425 del Código del Trabajo -en adelante CT-, dentro del párrafo 1 del Capítulo II del Libro V, que trata "De los principios formativos del proceso", que los procedimientos del trabajo serán orales, públicos y concentrados y que primarán en ellos los principios de la inmediación, impulso procesal de oficio, celeridad, buena $f e$, bilateralidad de la audiencia y gratuidad. Principios todos que apuntan, en un plano ideal, a lograr un proceso expedito tanto por su estructura y características prớcedimentales propiamente tales, como también por el ánimo de colaboración con el cual deben llegar a él las partes, de rectitud y honradez, como se desprende de la buena fe sobre la cual expresamente se ha formado el proceso y que en dicho sentido constituye una de sus cualidades inmanentes.

Puede observarse que, a diferencia de, por ejemplo, la inmediación, el impulso procesal de oficio y la gratuidad, cuya efectividad depende principalmente del mismo tribunal, y en general, de la administración de justicia, la buena fe exige una actividad positiva de las partes para ser satisfecha, siendo, más que un principio del procedimiento, un deber que va dirigido exclusivamente a ellas, al demandante y demandado, al trabajador y al empleador, de ajustar su conducta y todas sus actuaciones dentro del procedimiento acorde a sus mandatos $^{23}$. Se entiende que ordenarle al tribunal actuar de buena fe es algo, en teoría, innece-

\footnotetext{
${ }^{20}$ Montero, J., “Sobre el mito...'(n. 1), pp. 316 y ss.

${ }^{21}$ PICO I JUNOY, J., op. cit. (n. 2), p. 5.

22 CARreta, F., op. cit. (n. 5), p. 102.

${ }^{23}$ Respecto de la Ley de Enjuiciamiento Civil española, Montero Aroca señala que esta "no convierte a la buena fe procesal en un principio del proceso, pues entonces el mismo afectaría a todos los que hacen ese proceso, incluidos los jueces y magistrados, sino que se limita a imponer un deber a algunas de las personas que intervienen en el proceso, bien entendido que se trata solo de las partes y de los profesionales que las defienden". Y en efecto, así ha sido plasmada la buena fe en dicha ley, como un deber. En el caso de nuestro procedimiento laboral, y pese a que se ha consagrado como un "principio", la situación no parece ser distinta, traduciéndose en deberes que recaen sobre las partes. La observación de Montero Aroca en: MONTERO, J., "Sobre el mito...'(n. 1), p. 298.
} 
sario. Así, y ciñéndonos a la satisfacción estricta de lo que parece implicar este principio, podemos concluir que el legislador habría proscrito dentro del nuevo procedimiento laboral el que las partes hicieran una defensa centrada en resguardar sus propios intereses, como es natural a un conflicto -que la RAE ha definido como combate, lucha, pelea- para imponer un ánimo de colaboración, en que ambos, actor y demandado, proporcionen al juez todos los medios a su alcance, para junto a él esclarecer la verdad de los hechos y llegar a la solución justa, de lo que a ese modo de ver, en vez de ser un enfrentamiento de posiciones o intereses contrapuestos, puede más bien ser calificado como un mal entendido o una simple diferencia de opiniones, que todos han de desear -una vez expuesta la situación al tribunalaclarar prontamente.

Defender una posición que se estime "más débil" que la de la contraparte, o no colaborar aportando antecedentes relativos a la pretensión de la contraria, sea por simple desinterés o por inercia, serían conductas contrapuestas a esta buena fe, que exige una participación activa so pena de ciertas sanciones.

\subsection{CONTROL DEL DEBER DE OBSERVAR LA BUENA FE}

Se trata, en efecto, de un "deber de buena fe en el procedimiento" que, de momento que no puede ser forzado "en el fondo" -por tratarse de una disposición subjetiva de las partes a colaborar recta y honradamente entre sí, cuestión de suyo antinatural- es forzado "en la forma", en cuanto la parte necesariamente habrá de ajustar su conducta a las exigencias emanadas del deber de buena fe si no desea ser perjudicada -como se verá más adelante-.

En cuanto a las medidas generales que el legislador ha previsto para dirigir la conducta de los litigantes acorde a este deber, el artículo 430 del CT dispone que "los actos procesales deberán ejecutarse de buena fe, facultándose al tribunal para adoptar las medidas necesarias para impedir el fraude, la colusión, el abuso del derecho y las actuaciones dilatorias", pudiendo el juez rechazar de plano las actuaciones que a su juicio hayan sido hechas con ese solo fin. Para dicho efecto, se entenderá que son actuaciones dilatorias "todas aquellas que con el solo objeto de demorar la prosecución del juicio sean intentadas por alguna de las partes", pudiendo la parte afectada por la resolución que así lo declare, reponer para que sea resuelta en la misma audiencia.

Es decir, es el juez el principal encargado de cautelar la observancia de la buena fe -lo que reafirma la advertencia de que esta va dirigida a las partes-, para lo cual se le han otorgado amplias potestades que le permiten asegurar que los litigantes $-\mathrm{y}$ principalmente el demandado, quien naturalmente puede ser más reacio dado el contexto- colaboren y participen de manera activa; no solo evitando actuar de mala fe, como sería recurriendo al fraude, la colusión o el abuso del derecho, sino que también cautelando que no se incurra en otras conductas que puedan considerarse deliberadamente dilatorias, para cuya apreciación el juez goza de una amplia discrecionalidad, pudiendo, curiosamente, presumir la mala fe, esto es, el dolo, de la parte que realiza o solicita la actuación que califica como dilatoria. 
Pablo Cifuentes / El deber de buena fe en los procedimientos laborales: noción, manifestación y problemática

\subsection{MANIFESTACIONES NORMATIVAS DE LA BUENA FE}

Se exponen en este punto algunas de las manifestaciones normativas del deber de buena fe presentes dentro de la regulación del procedimiento laboral. La intención no es más que exponerlas y referirse a ellas de manera sucinta. Las críticas y problemáticas asociadas a estas serán tratadas en el título siguiente, haciendo presente desde ya que, coincidiendo con Hunter, lo nocividad no está en la consagración de deberes negativos o de abstención ${ }^{24}$-que por lo demás, ya estaban presentes en nuestro CPC-, sino en la exigencia de observar determinadas conductas o deberes positivos.

\section{a) Imposibilidad de solicitar la nulidad por quien ha originado el vicio o concurrido a su materialización}

Una manifestación del principio de buena fe puede encontrarse en el inciso final del artículo 429 del CT, el cual dispone que "no podrá solicitar la declaración de nulidad la parte que ha originado el vicio o concurrido a su materialización". Se trata de una sanción del todo comprensible que no es más que una reiteración de lo dispuesto por el artículo 83 inciso 2 del CPC, el que a su vez se ha entendido como una extensión del principio de derecho civil nemo auditur propria turpitudinem allegans, esto es, que nadie puede aprovecharse de su propia torpeza, o más estrictamente, de su propio dolo ${ }^{25}$. Evita que una de las partes, maliciosamente, pretenda valerse de este recurso como un arma de resguardo para deshacer todo lo obrado, y que por supuesto, le perjudica.

\section{b) Responsabilidad por los perjuicios ocasionados por la interposición de medidas cautelares}

Respecto de las medidas precautorias prejudiciales que se hayan solicitado, el artículo 444 inciso 4 del CT, dispone, en lo que nos concierne, que "si no se presentare la demanda en el término de diez días contados desde la fecha en que la medida se hizo efectiva, esta caducará de pleno derecho y sin necesidad de resolución judicial, quedando el solicitante por este solo hecho responsable de los perjuicios que se hubiere causado". Esta norma básicamente reproduce lo dispuesto por el artículo 280 del CPC y pretende sancionar actos maliciosos que pudieran afectar al patrimonio de aquél sobre quien recae la medida.

\section{c) Rechazo de demandas cuya acción se encuentre manifiestamente prescrita}

Al igual que la antes expuesta, la presente es una disposición que puede interpretarse como relativa al principio de buena fe que afecta exclusivamente a la parte demandante. Así, el artículo 447 inciso 2 del CT dispone que "si de los datos aportados en la demanda se desprendiere claramente la caducidad de la acción, el tribunal deberá declararlo de oficio y no admitirá a tramitación la demanda respecto de esa acción". Evidentemente el fin primordial es el descongestionar al sistema judicial de causas inviables, mas se evita igual-

\footnotetext{
${ }^{24}$ HUNTER, I., op. cit. (n. 14), p. 152.

25 Tradicionalmente este principio se entiende comprendido en el artículo 1683 del Código Civil, cuando señala que no podrá solicitar la nulidad absoluta el que ha ejecutado el acto o celebrado el contrato, sabiendo o debiendo saber el vicio que lo invalidaba. Otra manifestación de este principio se encuentra en el artículo 1468 del mismo Código.
} 
mente la interposición de demandas con fines que pudieran ser maliciosos, de molestar a la contraparte.

\section{d) Deberes relativos a la declaración de los testigos}

A los testigos se les exige una declaración verídica y fidedigna respecto de los hechos sobre los cuales depondrán. Para asegurar ese fin -formalmente- el juez habrá de hacerlos prometer o jurar decir verdad sobre dichas circunstancias advirtiéndoles de la eventual comisión de delito de falso testimonio.

Así, el artículo $454 \mathrm{~N}^{\circ} 5$ inciso 4 del CT dispone que, "Los testigos declararán bajo juramento o promesa de decir verdad en juicio. El juez, en forma expresa y previa a su declaración, deberá poner en conocimiento del testigo las sanciones contempladas en el artículo 209 del Código Penal, por incurrir en falso testimonio".

Además, la parte que efectúe el interrogatorio deberá ceñirse a lo dispuesto por el artículo $454 \mathrm{~N}^{\circ} 6$ inciso 2 del CT, esto es, que las preguntas de dicho interrogatorio "no podrán formularse en forma asertiva, ni contener elementos de juicio que determinen la respuesta, ni referirse a hechos o circunstancias ajenas al objeto de la prueba, lo que calificará el tribunal sin más trámite".

\section{e) Probibición de la prueba ilícita}

El artículo $453 \mathrm{~N}^{\circ} 4$ inciso 3 del CT dispone, que "carecerán de valor probatorio y, en consecuencia, no podrán ser apreciadas por el tribunal las pruebas que las partes aporten y que se hubieren obtenido directa o indirectamente por medios ilícitos o a través de actos que impliquen violación de derechos fundamentales".

$\mathrm{Al}$ efecto, y al igual que las anteriores, esta no es una disposición que provoque mayores dificultades respecto de su legitimidad, por cuanto se limita a desincentivar la producción y adquisición de medios probatorios por vías ilícitas, que constituyen conductas positivas de mala fe. Las disposiciones problemáticas, que implican deberes positivos de conducta y vulneran los derechos de las partes, son las que veremos a continuación.

f) Actividad probatoria del juez, exclusión de prueba de parte y evitación de la paralización del procedimiento

$\mathrm{El}$ artículo 429 del CT contiene diversas manifestaciones del principio de buena fe, además, claro está, de los principios de celeridad y de impulso oficioso por parte del juez.

Este dispone en su inciso 1 que:

"el tribunal, una vez reclamada su intervención en forma legal, actuará de oficio. Decretará las pruebas que estime necesarias, aun cuando no las hayan ofrecido las partes y rechazará mediante resolución fundada aquellas que considere inconducentes. De esta resolución se podrá deducir recurso de reposición en la misma audiencia. Adoptará, asimismo, las medidas tendientes a evitar la paralización del proceso y su prolongación indebida y, en consecuencia, no será aplicable el abandono del procedimiento". 
Como se ha visto, el "principio de buena fe", que más que un principio, es un deber de colaboración dirigido a las partes y sus abogados, se manifiesta en muchas ocasiones - cosa curiosa por lo paradójica- en una presunción de mala fe o de negligencia respecto de uno de los litigantes por parte del juez. De mala fe, pues el procedimiento laboral está impregnado de una suerte de desconfianza en las actuaciones de las partes; y especialmente de aquellas del demandado, atribuyéndoles expresa o implícitamente intenciones negativas, en un verdadero juicio de moralidad.

Así, por ejemplo, tratándose de actuaciones que requieran de tiempo y por tanto "demoren" el procedimiento, el juez podrá rechazarlos de plano, discrecionalmente, en base a su propia convicción, recurriendo entonces, a una presunción de mala fe de la parte, de la cual esta solo podrá reponer, lo que no es más que una formalidad estéril; y en otros casos, la decisión ya no estará en el juez, en cuanto no le corresponderá efectuar una evaluación de la animosidad de las partes, sino que, como en el citado artículo 429 inciso 1, la ley simplemente le concede poderes para suplir tanto la negligencia o desidia de una de las partes como las posibles malas intenciones. De esa manera, el que el juez pueda decretar prueba no solicitada por las partes tiene por fin el suplir -aparentemente- dos eventuales "falencias" de las partes en el procedimiento: (i) en primer lugar, la negligencia de la parte que debía haber solicitado la prueba en un principio y no lo hizo ${ }^{26}$-el real interesado-, y (ii) en segundo lugar, el natural desinterés de aquella parte que omite ofrecer prueba que le pueda ser perjudicial y/o no desee hacer el trabajo de su contraparte.

En ambos casos sobresale el espíritu paternalista del legislador, que desconfía de la capacidad de las partes de defender de manera autónoma sus propios intereses -al solicitar prueba que correspondía a una de ellas- y soslaya su eventual negativa o falta de interés en solicitar una prueba que pudiera serles perjudicial, salvando su falta de colaboración al esclarecimiento de la verdad.

Lo mismo respecto de las medidas tendientes a evitar la paralización del proceso y su prolongación indebida. Se releva a una de las partes en la labor de dar curso progresivo al procedimiento -la interesada-, que pueda conducir a su paralización, y se procura evitar que la otra lo prolongue de manera indebida. Se hace patente entonces, aquel interés público que converge y finalmente predomina en el procedimiento laboral por sobre el interés particular de los involucrados, y es que ¿por qué se habría de forzar la continuación y finalización del procedimiento si las partes fueran dueñas de este y no manifiestan su interés en continuarlo?

\section{g) Facultad de estimar tácitamente admitidos los hechos alegados en la demanda}

Quizás una de las manifestaciones más significativas sea aquella relativa a los efectos de la rebeldía del demandado. Como observa Carretta, "el Código de procedimiento civil no se refiere expresamente al efecto de la rebeldía del demandado o contumacia de la parte, y así el vacío es llenado por interpretaciones que estiman que el silencio del demandado se

\footnotetext{
${ }^{26} \mathrm{Al}$ respecto, y como una muestra de lo apartado que se encuentra el procedimiento laboral del respeto a los derechos de los litigantes, Montero Aroca señala que bajo una concepción liberal del proceso "se estimaba evidente que si el juez hubiese podido acordar de oficio la práctica de medios de prueba se hubiere convertido en el auxiliar de una de las partes". MONTERO, J., "Sobre el mito... (n. 1), p. 305.
} 
traduce en su negación, cuestión que es recogida por la jurisprudencia nacional"27. Esa ha sido la noción tradicional dentro del proceso civil, modificada dentro del procedimiento laboral por el artículo $453 \mathrm{~N}^{\circ} 1$ del CT, por cuanto en su inciso 7 dispone que, "cuando el demandado no contestare la demanda, o de hacerlo no negare en ella algunos de los hechos contenidos en la demanda, el juez, en la sentencia definitiva, podrá estimarlos como tácitamente admitidos" 28 . Si bien la norma no consagra un reconocimiento tácito que opere de manera automática, de momento que dispone que el juez podrá estimarlos -no es un imperativo-, la jurisprudencia, en los hechos, lo ha aplicado prácticamente a rajatabla en todos aquellos casos en que el demandado -empleador- o no ha contestado o no ha controvertido los hechos ${ }^{29}$, permitiendo sostener que en materia laboral ha operado una inversión de la regla general que ha alterado la máxima de onus probandi emanada del artículo 1698 del Código Civil ${ }^{30}$.

En este sentido, contestar la demanda termina por volverse una carga procesal para el demandado, quien ante la amenaza de que su silencio o su falta de contradicción expresa a los hechos alegados por el demandante sean considerados una admisión tácita de aquellos, se verá forzado a comparecer y negar de manera expresa lo sostenido en el libelo por el actor. Por supuesto, se gana en celeridad -y es que el sistema de cargas en sí cumpliría con una función impulsiva ${ }^{31}$ - pero ello a costa de imponerle al demandado la presión de contestar e impulsar una acción de la que en principio no es responsable ni mucho menos tiene interés.

Se hace aquí patente la utilidad y propósito de este deber de buena fe a que finalmente es obligado al demandado, como una herramienta que suple las dificultades que la rebeldía entendida como negación de todos los hechos alegados puede provocar al demandante; siendo la principal, una mayor carga probatoria "toda vez que deberá hacerse cargo preponderantemente de la prueba e incluso el contumaz puede ganar el pleito aun en su ausencia" 32 . Así, para algunos autores, la imposición de esta carga al demandado resultaría justa, "porque el desobediente rompe el principio de colaboración que sí es cumplido por su contraparte al seguir adelante con el proceso" 33 . Es decir, se le sanciona por no ayudar a "la causa común" en la que se ha visto involucrado en calidad de demandado, pues lo que corresponde a la buena fe, entendida de esta manera, es que coopere activamente al esclarecimiento de la verdad postergando sus intereses personales. Se disuade o se sanciona su "egoísmo", dependiendo de si contestó o no, con la amenaza de una sentencia desfavorable.

\footnotetext{
${ }^{27}$ CARretTA, F., op. cit. (n. 5), p. 106.

${ }^{28}$ Esta norma debe ser concordada con el artículo 452 inciso 2 del CT, que dispone que "La contestación deberá contener una exposición clara y circunstanciada de los hechos y fundamentos de derecho en los que se sustenta, las excepciones y/o demanda reconvencional que se deduzca, así como también deberá pronunciarse sobre los hechos contenidos en la demanda, aceptándolos o negándolos en forma expresa y concreta."

${ }^{29}$ Caso en el cual el juez habrá de proceder a dictar sentencia de manera inmediata, de acuerdo al Artículo $453 \mathrm{~N}^{\circ} 3$ inciso final.

${ }^{30}$ Artículo 1698 inciso 1 "Incumbe probar las obligaciones o su extinción al que alega aquéllas o esta".

31 CARRETTA, F., op. cit. (n. 5), p. 106.

${ }^{32}$ CARRETTA, F., op. cit. (n. 5), p. 107.

${ }^{33}$ Ibid.
} 
h) Facultad de dar por acreditados hechos ante conductas obstacularizadoras de una de las partes en materia de prueba

Hemos agrupado aquí a dos situaciones distintas a las cuales se aplica una misma sanción. La primera, comprende aquellos casos en que una parte omite la exhibición de documentos que legalmente deben estar en su poder, habiendo sido ordenada su exhibición por parte del tribunal, y la segunda, los casos en que el llamado a confesar no se presenta $o$, compareciendo, se niega a declarar o contesta a las preguntas de manera evasiva. En ambos casos, la sanción consiste en la facultad del juez de dar por acreditados los hechos que pretendían probarse por dichos medios.

$\mathrm{Al}$ efecto, el artículo $453 \mathrm{~N}^{\circ} 5$ dispone en su inciso 2 que "Cuando, sin causa justificada, se omita la presentación de aquellos -instrumentos- que legalmente deban obrar en poder de una de las partes, podrán estimarse probadas las alegaciones hechas por la parte contraria en relación con la prueba decretada" y el artículo $454 \mathrm{~N}^{\circ} 3$ que "Si el llamado a confesar no compareciese a la audiencia sin causa justificada, o compareciendo se negase a declarar o diere respuestas evasivas, podrán presumirse efectivas, en relación a los hechos objeto de prueba, las alegaciones de la parte contraria en la demanda o contestación, según corresponda".

Las críticas que nos merece lo expuesto, pueden leerse a continuación.

\section{CRÍTICAS AL DEBER DE BUENA FE EN EL PROCEDIMIENTO LABORAL}

LA BUENA FE ES UN RESABIO INQUISITORIAL QUE VULNERA EL PRINCIPIO DE INOCENCIA Y DE NO DECLARAR CONTRA SÍ MISMO

Más allá del contexto ideológico autoritario en el que surge la buena fe-ligado al comunismo y socialismo- no podemos evitar constatar ciertas reminiscencias inquisitoriales en el deber que se impone al demandado de comparecer y defenderse expresamente bajo el riesgo de resultar condenado al tenor de lo solicitado por el actor; y lo mismo respecto de la admisión presunta de los hechos en la confesional y las sanciones a la "obstaculización" probatoria. Ello, de momento que en términos prácticos, el procedimiento laboral opera de una manera similar a como operaba el sistema inquisitorial, donde el imputado era tenido por culpable desde el inicio de la investigación, recayendo sobre él la responsabilidad de probar su propia inocencia ${ }^{34}$. En una suerte de derogación del principio de inocencia, la inactividad constituye el primer paso a una sentencia condenatoria.

Del mismo modo, tras la colaboración completa y veraz que impone el deber de buena fe, parece ocultarse otro resabio del oscuro legado de la inquisición. Dicho deber significará muchas veces la autoinculpación del demandado, pues en efecto, este no debe mentir ni guardar silencio respecto de los hechos considerados relevantes para el esclarecimiento de la verdad. Por ello, su participación acorde a la buena fe se acotará a la de ser un mero facilitador de toda aquella información que, pese a que lo perjudique en la defensa y conservación de sus intereses personales, sea considerada pertinente por el tribunal para la resolución de

${ }^{34}$ Benabentos, O. Teoria general del proceso. Tomo 2. Rosario: Editorial Juris, 2005, p. 115. 
la causa -parte del problema de la instrumentalización de los litigantes como fuentes de información en la búsqueda de la verdad, que será vista en el punto siguiente-. Todo lo cual nos hace evocar las metas del procedimiento inquisitorial: el reconocimiento de la culpabilidad del reo -siendo el mayor logro el arrepentimiento del penitente- y su reconciliación con el dogma católico. Esto último, también extensible al contexto del procedimiento laboral, donde puede entenderse como una reconciliación con la realización del Derecho objetivo, mediante el triunfo de la verdad material.

La vulneración del principio de inocencia, y de la garantía asociada a este de no ser obligado a declarar contra sí mismo, significa por lo demás una violación al debido proceso, del cual son partes integrantes.

Al contrario de lo que sostiene la que parece ser la posición dominante, estas garantías no solo rigen en materia penal, sino que se extienden a todo otro orden procesal como un presupuesto de existencia de un debido proceso, el cual constituye una garantía constitucional de las partes. Y el respeto a estas, ciertamente, no es algo facultativo. El artículo 8 $\mathrm{N}^{\circ} 2$ de la Convención Americana sobre Derechos Humanos, o Pacto de San José de Costa Rica, ratificado por Chile, dispone que "toda persona inculpada de delito tiene derecho a que se presuma su inocencia mientras no se establezca legalmente su culpabilidad", y que "durante el proceso, toda persona tiene derecho, en plena igualdad a las siguientes garantías": entre las cuales, en la letra " $\mathrm{g}$ ", se consagra el "derecho a no ser obligado a declarar contra sí mismo ni.a declararse culpable". Deberes que nuestro país, no estaría asumiendo y que son inconciliables con las imposiciones del principio de buena fe del procedimiento laboral.

Bien puede sostenerse que la presunción de inocencia solo sería aplicable tratándose de "delitos" y que por la misma razón, por formar parte del mismo numeral, el derecho de no declarar contra sí mismo estaría restringido al proceso penal, mas la Corte Interamericana de Derechos Humanos (CIDH), órgano jurisdiccional cuyo propósito mismo es aplicar e interpretar la Convención referida, a dicho lo contrario.

En sentencia de 2 de febrero de 2001, la CIDH sostuvo “(...) que el elenco de garantías mínimas establecido en el numeral 2 del artículo 8 de la Convención se aplica a los órdenes mencionados en el numeral 1 del mismo artículo, o sea, la determinación de derechos y obligaciones de orden "civil, laboral, fiscal o de cualquier otro carácter". Esto revela el amplio alcance del debido proceso; el individuo tiene el derecho al debido proceso entendido en los términos del artículo 8.1 y 8.2, tanto en materia penal como en todos estos otros órdenes" 35 .

B) SE INSTRUMENTALIZA A LAS PARTES COMO FUENTE DE INFORMACIÓN AL SERVICIO DE LA BÚSQUEDA DE LA "VERDAD"

Adherimos con Bordalí en cuanto sostiene que, finalmente, el problema no radica en que el juez y el proceso mismo propendan a la búsqueda de la verdad material o histórica -si bien el concepto de verdad, como explica el mismo Taruffo, férreo defensor de la figura

35 Párrafo 125, "Caso Baena y otros vs. Panamá", Sentencia de 2 de febrero de 2001, Corte Interamericana de Derechos Humanos, disponible en http://190.41.250.173/RIJ/BASES/jurisp/Corte/Panama/baena_ricardo_fondo.pdf 
Pablo Cifuentes / El deber de buena fe en los procedimientos laborales: noción, manifestación y problemática

del juez instructor y de los procesos "mixtos", es uno epistemológicamente inaprensible ${ }^{36}$, sino en la manera en que esos hechos son recabados por el juzgador ${ }^{37}$. Es decir, apoyamos que el error de fondo no está en procurar esclarecer "la verdad de los hechos", si esta es desentrañada de las alegaciones y pruebas ofrecidas por las partes ${ }^{38}$-bajo la noción tradicional de que los hechos serán los narrados por las partes, y no hay más hechos que esos-, sino en perseguir ese propósito de manera absoluta, como objeto preciado en sí mismo, aun a costa de vulnerar los límites del principio dispositivo y los derechos de las partes ${ }^{39}$. Lo dicho no solo abarca a las actuaciones probatorias de oficio por parte del juez, sino que por supuesto, incluye también a-los deberes de colaboración impuestos a los litigantes. Y es que el hecho de que se les compela a aportar medios probatorios, y en general, a contribuir al esclarecimiento de la pretensión ejercida por su contraparte -so pena, como hemos visto, de resultar perjudicados- constituye un claro abuso a su derecho de defensa, a someterse a un debido proceso, y finalmente a su autonomía. Como señala Damaska, se instrumentaliza a las partes como fuente de información al servicio de una "investigación oficial", lo que este autor identifica como algo propio de los Estados activistas ${ }^{40}$-aquellos que se valen del proceso judicial para implementar políticas de Estado-. Lo dicho tiene especial relevancia respecto de la prueba confesional, en que el demandado -o sus representantes- deben declarar fidedignamente sobre hechos propios, en la encrucijada de que, si no miente, se habrá perjudicado a sí mismo, y si no comparece o da respuestas evasivas, podrá estimársele confeso. A este respecto, Damaska sostiene que "sin tener nunca el control completo de las acciones procesales, ni ser nunca sujeto soberano a cargo de sus intereses procesales, la parte puede ser fácilmente convertida en objeto de la acción procesal, es decir, en fuente informativa", y más específicamente respecto de la confesional, que "de este modo, un proceso puro de implementación de políticas incorpora como una de sus características definitorias el deber de las partes procesales de responder verídicamente a las preguntas que les dirijan (...) deber (que) no está protegido por una serie de privilegios, ni siquiera por el privilegio contra la autoinculpación" ${ }^{41}$.

\footnotetext{
${ }^{36} \mathrm{Al}$ respecto puede consultarse TARUfFO, M. La prueba de los hechos. Madrid: Trotta, 2002.

37 Bordalí, A., "Los poderes del juez civil", en: De LA Oliva, A. y PAlomo, I. (coord.): Proceso civil. Hacia una nueva justicia civil. Santiago: Editorial Jurídica de Chile, 2007, p. 193.

38 Verdad que se desprendería del carácter dialéctico que el contradictorio aporta al proceso, que es el que permite, como explica Hunter, que "las partes desde sus parciales puntos de vista puedan ilustrar al juez acerca del contenido de su pretensión y resistencia, ayudando a formar la convicción sobre la verdad o falsedad de los hechos invocados", de momento que "si las actuaciones de las partes están conducidas por el cuidado de sus propios intereses, no cabe duda que agregarán los datos omitidos por la contraparte en su narración, negarán o rectificarán aquellos hechos que entiendan que no guardan relación con la verdad". HUNTER, I, op. cit. (n. 14), p. 168.

39 Bordalí ofrece un interesante ejemplo de este punto: "El juez inquisidor del Absolutismo no hacía mal en determinar, por ejemplo, la responsabilidad que le cabía al imputado en el intento de homicidio del Príncipe. Hacía mal en incoar de oficio su poder, en hacer su investigación en secreto, privando al imputado de su libertad, impidiéndole defenderse, afectando su integridad física con torturas, admitiendo todo tipo de pruebas ilícitas, etc.". BORDALt, A., op. cit. (n. 37), p. 194.

40 DAMASKA, M. Las caras de la justicia y el poder del Estado. Análisis comparado del proceso legal. Santiago: Editorial Jurídica de Chile, 2000, p. 283.

${ }^{41}$ Ibid.
} 
Por lo expuesto, y como conclusión a este punto, si el juez ha de buscar la verdad, que lo haga dentro de los hechos expuestos libremente por las partes, procurando no hacerlo "contra la libertad y dignidad de los ciudadanos" 42 .

\section{PRODUCE UNA RELEGACION DE LA FIGURA DEL ABOGADO, VULNERA EL DERECHO}

\section{DE DEFENSA Y ELIMINA EL PRINCIPIO DE CONTRADICTORIO}

En principio, como dice Damaska, la labor del abogado consiste en ser un defensor vigoroso de los intereses de su representado, mas "en un sistema judicial caracterizado por la tendencia a favorecer la implementación fluida de la política del Estado, no hay lugar para los abogados que sirven los intereses privados de un cliente" 43 .

En el caso del procedimiento laboral, en general, en que los intereses particulares se encuentran desplazados a un distante segundo lugar -en gran parte como consecuencia de las exigencias y limitaciones impuestas por el deber de buena fe- sucederá algo similar a lo que acusa el dicho autor. El abogado se verá impedido de llevar una defensa adecuada, como sí podría efectuar en caso de contar con libertad y autonomía para decidir cuándo y cómo actuar y cuándo guardar silencio -sin estar bajo constante amenaza de verse perjudicado por su reserva o de ser soslayado por la actividad oficiosa del juez-.

Finalmente, el abogado es relegado a la posición de un mero colaborador "recto y honesto" del juez, lo que nos lleva a sostener que, para el legislador de la reforma, este debe más lealtad a los fines del procedimiento que a los egoístas intereses de su cliente ${ }^{44}$.

Por ello, no es difícil concluir que de momento que las partes no son libres para decidir sus actuaciones dentro del procedimiento debido a la exigencia de acatar deberes positivos de conducta conforme con la buena fe procesal ${ }^{45}$, se vulnera el derecho de defensa consagrado por la Constitución Política en el artículo $19 \mathrm{~N}^{\circ} 3$, y seguidamente, el principio de contradictorio $^{46}$. Y es que la posibilidad de poder efectuar libremente una defensa en juicio es una garantía del contradictorio ${ }^{47}$, que como señala Alvarado Velloso, se encuentra "en las bases mismas de la idea de proceso, entendido (latamente) como método pacífico y dialéctico de debate entre dos partes contrapuestas ante un tercero imparcial" 48 . Principio que se ha entendido vinculado "con el propio respeto de la dignidad humana y los valores intrínsecos de la democracia", en cuanto correspondería al "ejercicio concreto del derecho de defensa a los fines de la formación del convencimiento del juez" ${ }^{49}$. Ello pues es este el que garantiza a las partes "su derecho de actuar de modo crítico y constructivo sobre la marcha del proceso

\footnotetext{
42 BORDALf, A., op. cit. (n. 37), p. 194.

43 DAMASKA, M, op. cit. (n. 40), p. 302.

44 Todo lo cual se condice con la apreciación de Palavecino del "resultado liberticida" de la tendencia socializante del proceso civil, tras la cual se oculta "la pretensión totalitaria de subordinación del derecho subjetivo de la persona a una mística "realización del Derecho objetivo". Palavecino, C., op. cit. (n. 11), p. 74.

45 LARROUCAU, M.M, op. cit. (n. 2), p. 77.

46 Ibid.

${ }^{47}$ Meror, A., "Iura Novit uria y decisión imparcial", en: Ius et Praxis vol. 13, N², p. 386. Talca: Universidad de Talca, 2007. [Disponible en http://www.scielo.cl/scielo.php?script=sci_arttext\&pid=S0718-00122007000200015\&lng=es\&nrm $=$ iso]

48 Citado en Ibid.

49 Citado en Ibid.
} 
y su resultado, pudiendo ejercer la defensa de sus razones antes de la decisión" y que excluye -en consecuencia- la consideración de las partes como objeto de pronunciamiento judicial ${ }^{50}$.

\section{D) DESIGUALDAD DE LAS PARTES}

Pero sincerando las cosas, ya sea porque esa fue siempre la intención del legislador de la reforma o porque los hechos han llevado a que así suceda en la práctica, el llamado principio de buena fe y sus efectos no recaen de manera equitativa sobre ambas partes, como se ha podido anticipar. Las exigencias de conducta y sanciones recaen especialmente sobre el demandado, y por lo general, siempre que este sea el empleador.

Imponer la buena fe dentro del procedimiento es de por sí algo ilusorio. Sitúa a las partes en una posición de colaboración mutua que es antinatural al conflicto. Es una imposición moralizante que pretende adaptar el comportamiento de ambas partes -demandante y demandado, mas. especialmente de este último-, a la ideología que sustenta al procedimiento, como un instrumento de opresión.

La buena fe desnaturaliza la calidad originalmente pasiva del demandado imponiéndole deberes y aplacando y limitando la defensa que normalmente este pudiera ejercer; todo ello bajo la amenaza de obtener, por su sola pasividad, una sentencia adversa. La pasividad, entonces, sin colusión, fraude, o abuso del derecho de por medio, pudiera interpretarse como mala fe, por el hecho de no colaborar activamente al esclarecimiento de los hechos. Finalmente, se impone al demandado una exigencia superior que al demandante dentro del proceso.

Este desbalance que facilita la buena fe, la torna en un especial y muy efectivo medio para suprimir la libertad de defensa del demandado, que generalmente será el empleador. El juez - que como hemos visto cuenta con facultades discrecionales para estimar una conducta como maliciosa, y en general, para hacer efectivas las sanciones derivadas de la falta de colaboración -por ejemplo, tener por tácitamente reconocidos los hechos alegados en la demanda- será reacio a perjudicar al trabajador, que a ojos de la sociedad es la parte "más débil" de la relación laboral, y por tanto, digna de una mayor protección frente a la parte "fuerte y generalmente abusiva" que es el empleador.

Los deberes de buena fe se presentan entonces como una herramienta idónea a ese efecto, para aplacar al poderoso forzándolo a colaborar con el más débil, en una malentendida igualación de fuerzas entre trabajador y empleador dentro del proceso. Sin embargo, dicha visión olvida que el derecho sustantivo ya ha hecho lo propio, y que al proceso las partes deben llegar como iguales frente al juez, sin que se manifieste una preferencia por alguno de ellos o se repare en sus cualidades personales. Lo dicho, acorde a lo dispuesto por el artículo 1 inciso 1 de la Constitución Política, que consagra que "las personas nacen libres e iguales en dignidad y derechos", el artículo $19 \mathrm{~N}^{\circ} 3$, que asegura a todas las personas "la igual protección de la ley en el ejercicio de sus derechos" y a un "procedimiento e investigación racionales y justos"; todo reafirmado por el ya visto artículo $8 \mathrm{~N}^{\circ} 2$ de la Convención Americana sobre Derechos Humanos que se refiere expresamente a la "plena igualdad" que debe existir en el goce de las garantías para un debido proceso.

${ }^{50} \mathrm{Ibid}$. 


\section{CONCLUSIÓN}

La buena fe procesal, al igual que la buena fe como principio general del Derecho, es un concepto jurídico indeterminado "con el que se pretende moralizar las conductas humanas e introducir reglas morales, éticas y sociales al ámbito procesal" 51 . Esta tiene sus orígenes en ideologías de tipo autoritaria, que postergando los derechos individuales en favor de los intereses públicos, tergiversaron los fines del proceso como medio pacífico de resolución de conflictos intersubjetivos de intereses, utilizándolo como un medio de realización y cumplimiento de políticas de Estado. Ello, pues "cuando se parte de la concepción autoritaria, que ve en el derecho, ante todo, la voluntad del Estado, y en la observancia del derecho el respeto a la autoridad, resulta que también en la definición de la finalidad de la jurisdicción queda én la sombra el interés individual en la defensa del derecho subjetivo, y surge en primer plano el interés público en la observancia del derecho objetivo" 52 .

Para dichas ideologías, ese fin solo puede lograrse una vez alcanzada la verdad material o verdad verdadera, que es la que existe en la realidad más allá de la exposición sesgada y egoísta que las partes efectúan de los hechos. En este sentido, el principio de buena fe se presenta como un instrumento de coacción apropiado a dicho efecto, que debilita la autonomía y el derecho de defensa de las partes, instrumentalizándolas para dirigir su conducta a la concreción de las metas estatales.

Todo lo expuesto resulta en una grave lesión de las garantías y derechos de los particulares, que no se condice con el respeto que un Estado liberal y democrático de Derecho debe profesar por sus ciudadanos, y entra en abierta contradicción con las disposiciones de nuestra Constitución Política, así como de otros pactos internacionales. Por ello, urge un replanteamiento de la situación actual que concilie las normas del procedimiento laboral con los principios de un debido proceso, lo cual -respecto del caso concreto del principio de buena fe- no pasa por una legitimación de actuaciones dolosas, sino por una proscripción de las mismas sin la imposición de patrones conductuales liberticidas.

\section{BIBLIOGRAFÍA}

Aguad, A. y Pizarro, C. "Obligaciones y Responsabilidad Civil", en Revista Chilena de Derecho Privado $\mathrm{N}^{\circ} 14,2006$.

BENABENTOS, O. Teoría general del proceso. Tomo 2. Rosario: editorial Juris, 2005.

BENfTEZ, E. "Reflexiones en torno a la propuesta de reforma al procedimiento civil chileno: II Principios procesales relativos a las partes", en: Revista Chilena de Derecho vol. 34, No 3. Santiago: Pontificia Universidad Católica, 2007. Disponible en: http:/www.scielo.cl/sielo.php?pid=s0718$34372007000300014 \&$ sript $=$ si_arttext [consultado el 30 de diciembre de 2010]

Bordali, A., "Los poderes del juez civil", en: De la Oliva, A. y Palomo, I. (coord.). Proceso civil. Hacia una nueva justicia civil. Santiago: Editorial Jurídica de Chile, 2007.

51 HUNTER, I., op. cit. (n. 14), p. 178.

52 Calamandrei citado en MONTERO, J., "Sobre el mito... (n. 1), p. 302. 
Pablo Cifuentes / El deber de buena fe en los procedimientos laborales: noción, manifestación y problemática

Carretta, F. "Deberes Procesales de las partes en el Derecho Procesal Civil chileno: Referencia a la buena fe procesal y al deber de coherencia", en: Revista Chilena de Derecho vol. 21, No 1 . Santiago: Pontificia Universidad Católica de Chile, 2008. Disponible en: http://www.scielo.cl/pdf/revider/v21n1/art0.5.pdf [consultado el 30 de diciembre de 2010]

DAmaska, M., Las caras de la justicia y el poder del Estado. Análisis comparado del proceso legal. Santiago: Editorial Jurídica de Chile, 2000.

HunTER, I. "No hay buena fe sin interés: La buena fe procesal y los deberes de veracidad, completitud y colaboración", en: Revista de Derecho vol. XXI, N², 2008. Disponible en: http://www.scielo.cl/pdf/revider/ v2 $\ln 2 /$ art07.pdf [consultada 30 de diciembre de 2010].

LARROUCAU, M.M. "La buena fe procesal y el deber de colaboración de las partes en los procedimientos laborales", en: Revista Chilena de Derecho del Trabajo y de la Seguridad Social, vol. 1, N ${ }^{\circ}$ 1. Santiago: Universidad de Chile, 2010.

MeroI, A., "Iura Novit uria y decisión imparcial", en: Ius et Praxis vol. 13, $\mathrm{N}^{\circ} 2$. Talca: Universidad de Talca, 2007. [Disponible en http://www.scielo.cl/scielo.php?script=sci_arttext\&pid=S0718- 001220070002000158 lng $=e s \&$ nrm $=$ iso ]

Montero, J. Los Principios Políticos de la nueva Ley de Enjuiciamiento Civil. Los poderes del juez y la oralidad. Valencia: Tirant lo Blanch, 2001.

Montero. J. "Sobre el mito autoritario de la buena fe procesal', en: MonTero, J. (coord.). Proceso Civil e Ideologia. Valencia: Tirant lo Blanch, 2006.

PALAVECINO, C. "El retorno del inquisidor. Las potestades judiciales en materia probatoria en el Procedimiento Laboral chileno", en: Revista Laboral Chilena, № 173, 2009.

PICO I JUNOY, J. El principio de la buena fe procesal. [Disponible en: http://www.justiciayderecho.org/revista4/articulos/EL\%20PRINCIPIO\%20DE\%20\%LA\%20BUENA\%20FE\%20PROCESAL\%20 Joan\%20Pico\%20i\%20Jonoi.pdf]

ROMERO, A. "El principio de la buena fe procesal y su desarrollo en la jurisprudencia, a la luz de la doctrina de los actos propios", en: Revista Chilena de Derecho vol. $30, \mathrm{~N}^{\circ} 1$. Santiago: Pontificia Universidad Católica de Chile, 2003.

TARUfFo, M. La prueba de los hechos. Madrid: Trotta, 2002. 